\title{
Early pregnancy loss in aged mares: probable causes and possible cures
}

\author{
Biörn P. B. Rambags, Ben Colenbrander and Tom A. E. Stout \\ Department of Equine Sciences, Section of Reproduction; Utrecht University, Utrecht, the Netherlands
}

\begin{abstract}
Summary
During the last 20 years, advances in equine reproductive medicine have led to an appreciable increase in the per cycle pregnancy rate and a dramatic fall in the incidence of abortion due to twin pregnancy. On the other hand, the rate of early pregnancy loss (EPL) has altered little, and EPL remains a poorly understood but significant cause of economic loss to the breeding industry. Even in young healthy mares, approximately $10 \%$ of detected pregnancies are lost during the first 5 weeks of gestation while, in older mares, the problem is even more acute with many embryos succumbing before the first pregnancy check, probably as a result of either unresolved post-mating endometritis, a deficient oviductal environment or chromosomal abnormalities. Of course, there is no way of preventing EPL due to chromosomal abnormality and, while there is also no cure for oviductal insufficiency per se, In vitro fertilization (IVF) and gamete intrafallopian transfer (GIFT) offer possible, though as yet expensive, solutions to subfertility of oviductal origin. More practically, minimal contamination breeding and rapid intervention to prevent the escalation of post-breeding endometritis can dramatically improve the pregnancy rate and reduce EPL. Similarly, ensuring that mares are in good general health and body condition, and avoiding stress during early pregnancy will reduce the likelihood of EPL. With regard to specific therapies, progestagen supplementation will obviously prevent EPL due solely to falling progesterone levels, but is too often used without any clear evidence of luteal inadequacy. Furthermore, of the many progestagens on the market, only altrenogest (Regumate ${ }^{\circledR}$ ) and progesterone-in-oil have actually been proven to prevent EPL in the face of luteolysis. Finally, while chemical and physical curettage appear to reduce the severity of chronic degenerative endometritis, ET may represent a more rewarding approach to the mare with significant uterine deficiencies.
\end{abstract}

Keywords: Horse, pregnancy loss, age, cause, cure

\section{Embryonaler Fruchttod bei älteren Stuten: mögliche Ursachen und Therapieansätze}

Die Fortschritte in der equinen Reproduktionsmedizin der letzten 20 Jahre haben zu einem erwünschten Anstieg der Trächtigkeitsraten und einem drastischen Abfall der Aborte aufgrund von Zwillingsträchtigkeiten geführt. Im Gegensatz dazu hat sich jedoch die Anzahl der Verluste in der Frühträchtigkeit (EPL = early pregnancy loss) nur wenig verändert. EPL, ein nach wie vor wenig geklärtes Problem, ist einer der Hauptgründe ökonomischer Verluste in der Zuchtbranche. Sogar bei jungen, gesunden Stuten ist ein embryonaler Fruchttod in den ersten 5 Gestationswochen bei ca. 10 \% der nachgewiesenen Trächtigkeiten zu verzeichnen. Bei älteren Stuten ist das Problem akuter und handelt es sich überwiegend um das Absterben von Embryonen vor der ersten Trächtigkeitsuntersuchung. Ursachen sind wahrscheinlich persistierende Endometritiden nach der Belegung, suboptimales Eileitermilieu oder chromosomale Abnormalitäten. Es ist natürlich nicht möglich, durch chromosomale Schäden verursachte EPL präventiv zu beeinflussen oder Insuffizienzen im Bereich des Eileiters zu heilen. In vitro Fertilisation (IVF) und Gametentransfer direkt in den Eileiter stellen eine gute, jedoch teure Lösung bei Subfertilitäten, die durch das Ovidukt hervorgerufen werden, dar. In der Praxis ist es leichter, durch eine optimale Zuchthygiene und eine rechtzeitige Intervention Therapie von Endometritiden nach der Belegung die Trächtigkeitsrate zu verbessern. Weiterhin führt eine gute Gesundheit und Konstitution bei gleichzeitigem Vermeiden von Stress während der Frühträchtigkeit zu einer Verminderung der Wahrscheinlichkeit eines EPL. Aus therapeutischer Sicht, verhindert eine Progesteronsubstitution offenbar das Auftreten ausschließlich durch abfallende Progesteronkonzentrationen ausgelöster EPL. Diese Substitution wird jedoch häufig ohne eindeutige Hinweise auf das Vorliegen einer lutealen Dysfunktion angewandt. Zusätzlich ist von den vielen, auf dem Markt erhältlichen, Progestagenen nur für Altrenogest (Regumate ${ }^{\circledR}$ ) und Progesteron-in-Öl eine präventive Wirkung in Bezug auf EPL im Stadium der Luteolyse bewiesen. Abschließend ist zu bemerken, daß trotz der Tatsache, daß chemische und physikalische Kürettagen den Schweregrad chronisch degenerativer Endometritiden zu verringern scheinen, der Embryotransfer (ET) eine erfolgversprechendere Maßnahme bei Stuten mit schwerwiegenden uterinen Dysfunktionen darstellt.

Schlüsselwörter: Pferd, Trächtigkeitsverlust, Alter, Ursache, Heilung

\section{Introduction}

From the perspective of genetic improvement, the most desirable broodmares are those that have either proven their worth in competition or, better still, produced offspring that competed with distinction. Of course, by the time they have achieved these goals, the mares are usually of advanced age and are not the best candidates from a reproductive point of view, given that older mares tend to be more difficult to get pregnant and much more likely to suffer pregnancy loss (Ball 1988). Preventing EPL is, however, complicated by the fact that pregnancy loss is, by definition, diagnosed retrospectively and thus not amenable to treatment. However, preventative measures may be initiated if impending pregnancy loss is suspected because, for example, of a history of repeated EPL or signs that the mare is returning to oestrus. Nevertheless, it is often not entirely clear why EPL occurs, or therefore what the most logical approach to prediction and/or prevention 
might be. The aim of this review is to summarise the probable causes of EPL in aged mares and the utility of treatments aimed at ameliorating this problem.

\section{Timing and probable causes of EPL in aged mares}

Fertilization rates in mares are high irrespective of maternal age (approaching 90\%: Ball et al. 1986, Ball et al. 1989), but dramatic differences exist in the incidence and timing of pregnancy loss between young and aged mares. In short, normal young mares suffer very little embryonic loss before the time of first pregnancy examination, a peak of EPL during days 15-35 of gestation (5-15\% of all detected pregnancies) and only sporadic abortions later in pregnancy (Morris and Allen 2002). By contrast, aged mares suffer much higher embryonic losses during both the oviductal (days 0-6) and early uterine (days 6-16) periods (Ball et al. 1986, Ball et al. 1989). And while days 15-35 still represents the peak EPL period in aged mares ( $>20 \%$ of detected pregnancies), abortion during later gestation is also much more common than in younger animals (Morris and Allen 2002).

\section{EPL during oviductal retention}

The rate of embryonic death during days 2-4 after ovulation is much higher in aged than in young mares (Ball et al., 1986, Ball et al. 1989). In addition, transfer of day 4 (Ball et al. 1989) or day 7 (Vogelsang and Vogelsang 1989) embryos to fertile recipients results in lower pregnancy rates if those embryos are derived from older mares. All in all, this suggests that embryos from aged mares are less viable, either because of intrinsic abnormalities or because the oviductal environment is less conducive to adequate development. With respect to intrinsic defects, it is generally accepted that chromosomal abnorm-alities are the most common cause of embryonic death in women and that their incidence increases with advancing maternal age (for review see Wilton 2002). By analogy, chromosomal aberrations are often proposed as a cause of EPL in mares even though karyotypic analysis has provided little evidence for their occurence (King 1990, Lechniak et al. 2002).

Recently, fluorescent in situ hybridisation (FISH) has emerged as a powerful tool for identifying abnormalities of chromosome number, and has been used to demonstrate mixoploidy in macroscopically normal embryos recovered from both women (Delhanty et al., 1997) and cows (Viuff et al. 1999). Similarly, we recently usd 2-chromosome FISH to demonstrate that normal looking day 6-7 horse embryos can contain large numbers of chromosomally abnormal cells, although the proportion of affected embryos appears to be low (unpublished data). This finding confirms the suspicion that horse embryos can contain gross chromosomal anomalies that may compromise viability, and while it is likely that such abnormalities are more common in older mares, there is obviously no way to prevent their leading to embryonic death. Given the prolonged period that an equine embryo spends in the oviduct, it is also possible that salpingitis (which is more common in mares $>15$ years of age: Saltiel et al. 1986) or impaired oviduct secretory activity could affect embryo development. Unfortunately, oviductal pathology is difficult both to definitively diagnose and to treat.

\section{EPL after entry into the uterine lumen}

The second period of heightened EPL in aged mares is when the embryo arrives in the uterus at around day 6 after ovulation. A proportion of these losses are probably an expression of earlier abnormalities, while a second significant proportion is undoubtedly the result of unresolved post-breeding endometritis. On average, aged mares are less able to adequately clear the physiological inflammatory response to mating or insemination because of deficiencies in uterine contractility, lymphatic drainage, cervical and/or vulval conformation (for reviews see Katila 1996, Troedsson 1999). If the inflammation is not resolved by the time the embryo enters the uterus, EPL may result from infection of the embryo or by stimulation of luteolysis (Adams et al. 1987).

\section{Failure of luteal maintenance}

Maintenance of pregnancy is absolutely dependent on progesterone produced by the primary corpus luteum (CL), at least until endometrial cup formation at around day 35 after ovulation. Furthermore, in order to 'switch off' endometrial PGF2a production and ensure luteal maintenance, the developing conceptus must migrate continuously throughout the uterine lumen during days 6-16 after ovulation (McDowell et al. 1988); a phenomenon known as the 'maternal recognition of pregnancy' (MRP). In practice, it is possible that large or multiple endometrial cysts may impede conceptus mobility and thereby endanger CL maintenance. MRP may also fail as a result of a 'small-for-dates' conceptus failing to secrete sufficient signal before cyclical luteolysis intervenes.

\section{Untoward luteolysis}

There are, of course, other causes of inadequate maternal plasma progesterone concentrations; these consist primarily of stimuli that trigger PGF2a release, since primary luteal insufficiency does not appear to be a clinically significant problem in mares (Allen 2001). On the other hand, luteolysis can be triggered by ascending endometritis or as a delayed sequel to post-breeding endometritis. Luteolysis can also be triggered by endotoxaemia and prostaglandin release elsewhere in the body, for example during severe gastro-intestinal disease (Daels et al. 1991). In addition, while the ability of the endometrium to release PGF2 $a$ is suppressed during days 10-16 of pregnancy, it returns during days 18-35 (Stout and Allen 2002) and, during this later period, any stimulus capable of triggering oxytocin release, such as uterine trauma of the sort needed to reduce a twin to a singleton pregnancy, may trigger luteolytic PGF2a release. Indeed, the developing horse conceptus appears to tread a remarkably precarious endocrinological path during which untoward fluctuations in systemic hormone concentrations may undermine luteal activity, as witnessed by the luteolytic effects of both exogenously administered hCG (Allen 1975) and oestrogens (Stout and Allen 2001).

\section{Failure of conceptus nutrition}

While chronic degenerative endometritis is thought classically to result in pregnancy loss late in gestation as the fetus out- 
grows the ability of a poorly developed placenta to meet its nutritional and respiratory needs, it may also result in EPL in the period between fixation (day 16-17) and formation of a true allantochorionic placenta (day 40 of gestation). In these cases, it is likely that the conceptus either fails to imbibe sufficient histotrophe from, or is unable to adequately interdigitate, with the surrounding dysfunctional endometrium.

\section{Later pregnancy losses}

Pregnancy loss after day 35 of gestation is uncommon and sporadic with causes including missed twins, specific infections (e.g. EHV-1 or EVA) and severe maternal illness or stress. Late abortions are, however, more frequent in older mares because of endometrial degeneration or ascending placentitis via an incompetent vulva and/or cervix.

\section{Possible cures}

Correction of anatomical defects

In cases where (a risk of) EPL stems from an identifiable anatomical defect, the obvious first protective step is to remedy that defect. In particular, incompetence of any of the three barriers to ascending microbial colonisation of the uterus (the vulva, vestibulo-vaginal sphincter and cervix) will increase the mare's susceptibility to both mating-induced endometritis and later ascending endometritis or placentitis. Poor vulval conformation can usually be successfully remedied by a simple Caslick's operation (closure of the vulval orifice to the level of the pelvic floor), although in recalcitrant cases the more invasive Pouret's procedure (separating the connection between vagina and rectum) or a urethral extension may be required to prevent recurrent pneumo or urovagina (Trotter 1999). Failure of the cervix to close properly is an even more serious problem, and while closure of the external os with a purse string suture or surgical reconstruction of the internal os are both possible, the long-term prognosis is guarded because the fibrosed cervix is likely to re-tear during subsequent foalings (Trotter 1999).

\section{Controlling mating-induced endometritis}

Given that endometritis is probably the primary cause of subfertility in aging mares, breaking the cycle of irritation and inflammation initiated by mating is a vital part of fertility management. This is best achieved by adherence to the principles of 'minimal contamination breeding' (Kenney et al. 1975) i.e. artificial insemination rather than natural mating and induction of ovulation to ensure a single insemination per oestrus. Further to this, rapid identification and treatment of post-insemination endometritis by judicious use of uterine lavage, ecbolics (oxytocin or PGF2a) and antibiotics can dramatically improve the chances of pregnancy (for review see Troedsson 1999).

\section{Correction of endometrial defects}

Since large or numerous endometrial cysts appear to interfere with pregnancy maintenance, removal using either a polypectomy snare or an Nd:YAG laser under transcervical endoscopic control may reduce the likelihood of EPL. Where the endometrium shows extensive fibrotic degeneration, however, the prognosis is poor and although both chemical (e.g. with kerosene) and physical curettage have been suggested to improve endometrial quality enough to allow the establishment of pregnancy, this may not always be sufficient to avoid later abortion. For this reason, in cases of severe endometrial degeneration, embryo transfer may be a more successful way of producing a viable foal.

\section{Hormonal treatments to prevent EPL}

Only pregnancy loss threatened as a result of inadequate maternal circulating progesterone concentrations is truly amenable to prevention by hormonal treatment. And while a one-off injection of a GnRH analogue, such as buserelin, during days 9-11 after ovulation has been claimed to improve the pregnancy rate and reduce the likelihood of EPL (Newcombe et al. 2001), since there is no evidence that this treatment either boosts circulating progesterone levels or suppresses the ability of the endometrium to release PGF2a (Stout et al. 2002) it is unsure how, or if, this treatment really works. Of course, the most logical way to address inadequate maternal progesterone levels is exogenous progesterone supplementation. In the case of repeated EPL, this should be started soon after ovulation (4-6 days later). Otherwise, progesterone supplementation should be initiated as soon as a threat is identified (e.g. onset of endotoxaemia, signs of a return to oestrus). In practice, confirmation that blood progesterone levels are indeed too low $(<2 \mathrm{ng} / \mathrm{ml})$ is often neglected and progesterone supplementation is frequently initiated without a logical rationale (e.g. when previous EPL occured despite CL maintenance) or simply to preclude any possibility of progesterone insufficiency. Similarly, while there is little rationale for continuing progesterone supplementation beyond day 120 of gestation, when a viable feto-placental unit will itself produce enough progestagens to maintain pregnancy, supplementation is often continued for the entire pregnancy because of a fear that later abortion may be wrongly attributed to cessation (Allen 2001). In the instance of endotoxaemia, elective surgery or uterine trauma (for example during transvaginal ultrasound guided twin reduction), it is prudent to further reduce the likelihood of PGF2a release and/or toxaemia by administration of flunixin meglumine. Finally, if progestagen supplementation is to be used it should be borne in mind that of the many products available on the market, only altrenogest (Regumate ${ }^{\circledR}$ )(McKinnon et al. 2000) and progesterone-in-oil have been proven to maintain pregnancy in the face of luteolysis .

\section{Conclusions}

EPL is almost certainly the most important cause of subfertility in aged mares. Of course, there is no cure for intrinsic embryonic abnormalities, but fertility and EPL can be considerably improved by correcting obvious defects in the anatomy of the mares reproductive tract, using minimal contamination breeding techniques and promptly and aggressively treating post-breeding endometritis. In cases of severe uterine or oviductal pathology, an alternative may be to circumvent 
the problem by embryo transfer, GIFT or IVF, although the latter two techniques are still in their infancy and subject to tight ethical controls in some European countries. Finally, while progesterone supplementation is undoubtedly a useful means of preventing EPL in the face of luteolysis, it is often used without any clear need and in the form of progestagens that have no ability to actually support pregnancy.

\section{Literature}

Adams G. P., Kastelic J. P., Bergfelt D. R. and Ginther O. J. (1987): Effect of uterine inflammation and ultrasonically-detected uterine pathology on fertility in the mare. J Reprod Fertil Suppl 35, 445454

Allen W. E. (1975): Pregnancy failure induced by human chorionic gonadotrophin in pony mares. Vet $\operatorname{Rec} 96,88-90$

Allen W. R. (2001): Luteal deficiency and embryo mortality in the mare. Reprod Domest Anim 36, 121-131

Ball B. A. (1988): Embryonic loss in mares. Incidence, possible causes, and diagnostic considerations. In: The veterinary clinics of North America. Equine practice. Reproduction, Ed: S.D. Van Camp, W.B. Saunders company, Philadelphia. 263-290

Ball B. A., Little T. V., Hillman R. B. and Woods G. L. (1986): Pregnancy rates at days 2 and 14 and estimated embryonic loss rates prior to day 14 in normal and subfertile mares. Theriogenology 26, $611-619$

Ball B. A., Little T. V., Weber J. A. and Woods G. L. (1989): Survival of day-4 embryos from young, normal mares and aged, subfertile mares after transfer to normal recipient mares. J Reprod Fertil 85, 187-194

Daels P. F., Stabenfeldt G. H., Hughes J. P., Odensvik K. and Kindahl $H$. (1991): Evaluation of progesterone deficiency as a cause of fetal death in mares with experimentally induced endotoxemia. Am J Vet Res 52, 282-288

Delhanty J. D., Harper J. C., Ao A., Handyside A. H. and Winston R. M. (1997): Multicolour FISH detects frequent chromosomal mosaicism and chaotic division in normal preimplantation embryos from fertile patients. Hum Genet 99, 755-760

Katila T. (1996): Uterine defence mechanisms in the mare. Anim Reprod Sci 42, 197-204

Kenney R. M., Bergman R. V., Cooper W. L. and Morse G. W. (1975): Minimal contamination techniques for breeding mares: techniques and preliminary findings. Proc $21^{\text {st }}$ Ann Conv Am Assoc Equine Prac, 327-336

King W. A. (1990): Chromosome abnormalities and pregnancy failure in domestic animals. In: Domestic animal cytogenetics, Ed: R.A. McFeely, Academic Press, San Diego. pp 229-250

Lechniak D., Wieczorek M. and Sosnowski J. (2002): Low incidence of diploidy among equine oocytes matured in vitro. Equine Vet J $34,738-740$
McDowell K. J., Sharp D. C., Grubaugh W., Thatcher W. W. and Wilcox C. J. (1988): Restricted conceptus mobility results in failure of pregnancy maintenance in mares. Biol Reprod 39, 340-348

McKinnon A. O., Lescun T. B., Walker J. H., Vasey J. R. and Allen W. $R$. (2000): The inability of some synthetic progestagens to maintain pregnancy in the mare. Equine Vet J 32, 83-85

Morris L. H. and Allen W. R. (2002): Reproductive efficiency of intensively managed Thoroughbred mares in Newmarket. Equine Vet J $34,51-60$

Newcombe J. R., Martinez T. A. and Peters A. R. (2001): The effect of gonadotropin-releasing hormone analog, buserelin, on pregnancy rates in horse and pony mares. Theriogenology 55, 1619 1631

Saltiel A., Paramo R., Murcia C. and Tolosa J. (1986) Pathologic findings in the oviducts of mares. Am J Vet Res 47, 594-597

Stout T. A. E. and Allen W. R. (2001) Oestrogens and pregnancy maintenance in the mare: For or against? Pferdeheilkunde 17, $579-582$

Stout T. A. E. and Allen W. R. (2002) Prostaglandin E2 and F2a production by equine conceptuses and concentrations in conceptus fluids and uterine flushings recovered from early pregnant and dioestrous mares. Reproduction 123, 261-268

Stout T. A. E., Tremoleda J. L., Knaap J., Daels P., Kindahl H. and Colenbrander B. (2002) Mid-diestrous GnRH-analogue administration does not suppress the luteolytic mechanism in mares. Theriogenology 58, 567-570

Troedsson M. H. T. (1999) Uterine clearance and resistance to persistent endometritis in the mare. Theriogenology 52, 461-471

Trotter G. W. (1999) The vulva, vestibule, vagina and cervix. In: Equine surgery, Eds: J. A. Auer and J. A. Stick, W.B. Saunders Company, Philadelphia. 558-574

Viuff D., Rickords L., Offenberg H., Hyttel P., Avery B., Greve T., Olsaker I., Williams J. L., Callesen H. and Thomsen P. D. (1999) A high proportion of bovine blastocysts produced in vitro are mixoploid. Biol Reprod 60, 1273-1278

Vogelsang S. G. and Vogelsang M. M. (1989) Influence of donor parity and age on the success of commercial equine embryo transfer. Equine Vet J Suppl. 8, 71-72

Wilton L. (2002) Preimplantation genetic diagnosis for aneuploidy screening in early human embryos: a review. Prenat Diagn 22, $512-518$

Björn P. R. Rambags

University of Utrecht

Department of Equine Sciences

Section Reproduction

Yalelaan 12

3584 CM Utrecht, the Netherlands

b.p.b.rambags@vet.u.nl 